\title{
Acupuntura: Conhecimento e Percepção de Professores Universitários
}

\section{Acupuncture: Knowledge and Perception of University Professors}

\author{
Márcia Maria Tavares Machado \\ Jessica da Costa de Oliveira \\ Álvaro Diogenes Leite Fechine
}

\author{
PALAVRAS-CHAVE: \\ - Acupuntura. \\ - Educação Médica. \\ - Medicina Tradicional Chinesa. \\ - Terapias Complementares.
}

Recebido em: 15/03/2011

Reencaminhado em: 25/08/2011

Aprovado em: 29/10/2011

REVISTA BRASILEIRA DE EDUCAÇÃO MÉDICA

\begin{abstract}
RESUMO
Esta pesquisa teve por objetivo identificar o conhecimento e percepção de professores universitários, médicos, sobre a acupuntura. Utilizou-se a abordagem qualitativa, realizando-se 15 entrevistas individuais com professores da Faculdade de Medicina da Universidade Federal do Ceará (UFC), em Fortaleza, Ceará, de junho a dezembro de 2010. O tempo médio de ensino desses professores na UFC foi de 22 anos, e a idade média de 55 anos.Observou-se que a maior parte dos entrevistados não buscava espontaneamente informações sobre acupuntura; poucos conheciam alguma contraindicação;e os que indicavam a acupuntura o faziam para alívio de dores; a quase totalidade apresentou opinião favorável ao oferecimento da acupunturaa usuários do SUS, bem como à sua inclusão na grade curricular como disciplina optativa ou como assunto coadjuvante em disciplinas afins. No entanto, poucos entrevistados admitem abordar este tema em sala de aula como terapêutica equivalente às opções alopáticas. Constatou-se que os professores demonstram interesse em práticas não convencionais e reconhecem a importância da inserção dessa temática nos currículos dos cursos de Medicina.
\end{abstract}

\section{ABSTRACT}

This study aimed to identify the knowledge and perception of medical school lecturers in relation to acupuncture. Qualitative methodology was employed, involving individual interviews with 15 teachers from various departments of the Ceará Federal University School of Medicine, held in Fortaleza, Ceará, between June and December 2010. The average teaching experience of the lecturers was 22 years and average age,55. It was found that most respondents did not spontaneously seek information about acupuncture; few knew any contraindications and those who recommended acupuncture, did so for the purposes of pain relief; almost all the respondents were in favor of acupuncture being offered to SUS patients, and of including acupuncture in the curriculum as an optional subject or supporting topic in related disciplines. However, few respondents admit addressing this topic in the classroom as form of treatment equivalent to allopathic options. We found that teachers demonstrate interest in unconventional practices and they acknowledge the importance of integrating this theme into the medical curriculum. 


\section{INTRODUÇÃO}

A Medicina Tradicional Chinesa (MTC) existe há mais de 5 mil anos e inclui técnicas de acupuntura, massagem (Tui-Na), exercícios respiratórios (Chi-Gung), orientações nutricionais (Shu-Shieh) e a farmacopeia chinesa (medicamentos de origem animal, vegetal e mineral) ${ }^{1}$.

A MTC e, portanto, a acupuntura definem que as funções orgânicas dependem de um equilíbrio entre corpo e meio externo. Desta forma, a acupuntura propõe que a saúde está diretamente ligada às funções psiconeuroendócrinas, às características herdadas e a fatores como nutrição, hábitos de vida, clima e qualidade do ambiente, entre outros ${ }^{2}$. Rompe, assim, com a visão fragmentada do corpo humano e com a unicausalidade das enfermidades.

Muitos estudiosos entendem que a acupuntura chinesa constitui, ao mesmo tempo, um estudo dos transtornos patológicos e um método terapêutico capaz de corrigi-los e de combatê-los ${ }^{3}$. A eficácia da acupuntura, bem como de outras técnicas que compõem a MTC, vem sendo comprovada por pesquisas em todo o mundo ${ }^{4-6}$.

Dados da Organização Mundial Saúde (OMS) apontam que, em países ricos, a maioria das pessoas busca tratamento com produtos naturais, por julgaremque estes sãomais seguros. Já nos países em desenvolvimento, $80 \%$ da população recorre à medicina tradicional para cuidados primários de saúde, devido à tradição cultural ou à falta de alternativas ${ }^{7}$. Em concordância com esta realidade, autores apontam o consenso de que os custos de um tratamento por meio da acupuntura são muito baixos ${ }^{8}$, principalmente quando comparados aos da medicina alopática, que envolve a participação de vários especialistas na abordagem de um único paciente e a repetição exaustiva de exames de rotina e de controle ${ }^{9-10}$

A despeito da grande adesão popular às práticas alternativas em saúde, seja por falta de opção ou por uma questão cultural, existe, entre os profissionais de saúde, resistência ou preconceito em aceitar a eficiência dessas terapias, mesmo quando atestadas cientificamente, como no caso da acupuntura. As medicinas ocidental e oriental, desde suas origens, assumiram posicionamentos distantes e algumas vezes divergentes, impedindo o diálogo entre as duas ciências. A ideologia ocidental rejeita os princípios da MTC, o que dificulta o desenvolvimento de pesquisas acerca da acupuntura, bem como sua difusão no meio acadêmico ${ }^{11-12}$.

O uso das novas terapias designadas como "alternativas", "paralelas" ou "complementares" à biomedicinatem crescido entre a população no Brasil e na América Latina, frente ao fracasso da medicina ocidental em tentar dar resposta a todos os males do corpo e, senão, da sociedade moderna. Estudiosos na temática apontam que essas terapias, entre elas a acupuntura, são derivadas de sistemas complexos tradicionais e têm sua própria racionalidade, imbricada em conhecimentos oriundos de séculos de experimentação e vivência. Desta forma, a acupuntura usa racionalidades e adota um paradigma centrado no indivíduo e na mente como promotora e recuperadora da saúde, e não simplesmente uma visão especializada dirigida ao diagnóstico e tratamento de patologias ${ }^{13-14}$.

Estudo realizado nos Estados Unidos demonstrou que 2,3 milhões de americanos fizeram uso recente da acupuntura. Os pesquisadores sugeriram entraves culturais, baixa taxa de encaminhamentos ou pequena disponibilidade como os principais responsáveis por esse resultado aquém do esperado ${ }^{15}$.

No Brasil, a acupuntura vem sendo incorporada como alternativa terapêutica, em geral associada aos procedimentos da medicina científica ocidental, em vários hospitais universitários, desde o início dos anos 1980, sendo legalmente considerada como especialidade médica desde $1995^{16}$. Após extensas discussões, o Ministério da Saúde aprovou,em maio de 2006, a Portaria 971/06, que institucionalizou as práticas alternativas e complementares e as inseriu no modelo assistencial do Sistema Único de Saúde (SUS) ${ }^{17}$. Também, outros profissionais da área da saúde, desde que normatizados por seus respectivos Conselhos Federais profissionais, passaram a ter o direito de exercer estas práticas ${ }^{18-19}$.

Poucos estudos têm abordado a opinião de professores acadêmicos sobre a inserção da Medicina Tradicional Chinesa na graduação dos cursos da área da saúde. Por outro lado, algumas pesquisas mostram que os alunos se apresentam receptivos ao tema e consideram importante este assunto, que deve ser abordado durante a graduação sob a forma de disciplina optativa ${ }^{20-22}$.

A deficiência de conhecimentos técnicos na prática clínica por alguns profissionais de saúde expõe pacientes a potenciais danos de saúde, visto que a instituição de sessões de acupuntura antes de o paciente receber um diagnóstico pode mascarar ou alterar sinais clínicos ${ }^{11}$. Diante das falhas da vigilância sanitária, o profissional médico deve estar atento para orientar o paciente, evitando desinformação, acesso inadequado e tratamentos ineficazes.

A partir dessas informações, surgiram alguns questionamentos e reflexões que motivaram a realização do presente estudo, tais como: os futuros profissionais médicos estão sendo estimulados por seus mestres a expandir suas opções de terapia considerando a MTC? Os professores médicos, como orientadores e padrão de referência para novas gerações, apresentam resistência em considerar e adotar a acupuntura como tratamento? Como buscam informações acerca da 
acupuntura?Encaminham pacientes para utilizar a acupuntura como terapêutica complementar ao modelo biomédico? O que pensam sobre o diálogo entre as medicinas ocidental e oriental no sentido de agregar valores para construir um modelo mais completo?

A partir dessas inquietações, este estudo teve por objetivo identificar o conhecimento e percepção de professores universitários da Faculdade de Medicina da Universidade Federal do Cearásobre a acupuntura.

\section{PROCEDIMENTO METODOLÓGICO}

O estudo apresenta uma abordagem qualitativa de investigação social, por sua natureza e adequação ao estudo de significados, aspirações, crenças e atitudes ${ }^{23}$. As pesquisas qualitativas são exploratórias, pois estimulam o livre pensar dos entrevistados. O pesquisador busca interpretar os fenômenos segundo a perspectiva dos participantes da situação estudada ${ }^{24}$. A metodologia qualitativa aborda o universo dos significados, motivos, aspirações, crenças, valores e atitudes, o que corresponde a um espaço mais profundo das relações, dos processos e dos fenômenos que não podem ser reduzidos a uma quantificação ${ }^{25}$. Esta pesquisa apresenta caráter exploratório, por serem ainda muito escassas, na literatura, produções empíricas ou conceituais acerca da questão demarcada na perspectiva aqui adotada.

Para a coleta das informações, foram identificados, na direção da Faculdade de Medicina da Universidade Federal do Ceará (UFC),os nomes de todos os professores médicos e respectivos departamentos. A partir dessa listagem por setores, selecionamos uma amostragem representativa de cada setor, por meio de sorteio. Para cada departamento sorteávamos um nome,que era contatado para esclarecimento dos objetivos da pesquisa e solicitação de sua participação. Quando algum deles recusava ou não dispunha de tempo para a entrevista, era realizado novo sorteio. No entanto, o tamanho da amostragem foi determinado por critérios de exaustividade do discurso e saturação das falas, em adequação com a ideologia qualitativa deste estudo ${ }^{25}$.

$\mathrm{Na}$ etapa seguinte, o professor sorteado era contatado para agendamento de entrevista semiestruturada, não diretiva, que se realizou com auxílio de gravador. A natureza não diretiva do questionário aplicado nos permitiu apreender a subjetividade do entrevistado a partir de seus sentimentos, percepções e vivências. As entrevistas ocorreram de julho a dezembro de 2010, no campus do Porangabussu, Faculdade de Medicina, da Universidade Federal do Ceará.

O projeto de pesquisa foi aprovado pelo Comitê de Ética da Universidade Federal do Ceará, Parecer n 44/08, obede- cendo aos princípios que regem as pesquisas realizadas com ser humano, conforme resolução do Conselho Nacional de Saúde 196/96.

As entrevistas foram transcritas na íntegra. Após essa etapa, realizamos uma leitura flutuante e, a seguir, procedemos à leitura atenta das falas. A partir da análise interpretativa do discurso dos sujeitos entrevistados, foram apreendidas as seguintes temáticas centrais: (a) importância da busca de informações sobre acupuntura para o exercício da docência; (b) conhecimento dos professores sobre acupuntura; (c) prática e ensino: divergências e convergências quanto à atuação por outros profissionais de saúde; (d) inclusão da acupuntura na grade curricular do curso de Medicina; (e) acupuntura: efeito placebo ou tábua de salvação?; (f) escolha terapêutica: um exercício de respeito à autonomia do paciente.

\section{RESULTADOS E DISCUSSÃO}

Para compor o estudo, foram entrevistados 15 professores da Faculdade de Medicina da UFC, dentre os quais 7 homens e 8 mulheres, apresentando média de idade de 55 anos (47-68 anos) e tempo médio de ensino na faculdade de 22 anos (237 anos). A pesquisa abrangeu todos os departamentos, tendo sido abordados aleatoriamente indivíduos das seguintes especialidades: ginecologia, obstetrícia, medicina do trabalho, anestesia, pediatria, neonatologia, medicina do adolescente, clínica médica, geriatria, gastroenterologia, patologia, nutrologia, oftalmologia, infectologia, cirurgia pediátrica e acupuntura médica.

\section{A Importância da Busca de Informações sobre Acupuntura para o Exercício da Docência}

Os discursos revelam que a maior parte dos entrevistados não busca espontaneamente informações sobre acupuntura, existindo apenas relatos singulares de experiência com esta terapêutica seja na condição de paciente que utiliza a MTC ou de profissional acupunturista. Entretanto, concordam em que o tema é bastante atual e recorrente no cotidiano médico, devendo, por isso, estar o docente em constante busca de evidências e ampliação de seu arsenal de conhecimentos, a fim de estar apto à sua função de orientador e facilitador do aprendizado. Em adição, uma minoria sublinha que, muitas vezes, a geração de informações sobrepuja a capacidade individual de absorção deste conhecimento e que por isso a acupuntura, considerada como tratamento adjuvante, desfruta de espaço reduzido e pouco explorado na academia:

O docente é um estudante privilegiado, é um estudante que fica estudando e deve estar preparado para estimular outras 
pessoas a estudar pelo menos durante o período em que são alunos. Esse profissional tem que ter um conhecimento amplo porque está formando opiniões. Imagine você um indivíduo nesta situação ignorar certas coisas, e o aluno fazer perguntas e ele, por desconhecimento, menosprezar aquele assunto e causar naquela pessoa que está em formação uma aversão. Então, ele estaria frustrando qualquer possibilidade de conhecimento. (Professor 10)

Já é tanta coisa que a gente tem que ver na disciplina que não cabe mais... não tem mais espaço pra a acupuntura. Acho que se houvesse espaço dentro do tempo de que eu disponho, poderia até procurar, mas até agora...Está faltando para outras coisas que são bem importantes também. (Professor 2)

Entendida como uma prática terapêutica complementar ao tratamento médico alopático, oferecendo uma visão holística do processo saúde-doença e com eficácia reconhecida na literatura médica, a acupuntura apresenta indicações em quase todas as especialidades médicas e vem mostrando aumento de demanda entre os pacientes das esferas pública e privada. Neste contexto de mudanças e reorganização de paradigmas da medicina ocidental, apreendemos dos relatos que a condição de docente determina a necessidade de constante atualização sobre as diversas opções de tratamento, tanto para estar apto à função de orientador, quanto para servir de exemplo e repasse de informação aos alunos. Em diálogo com as ideias apontadas por Queiroz ${ }^{26}$ e Capra $^{27}$, que já denunciavam a crise de paradigmas da medicina ocidental precipitada diante da visão integral do sujeito proposta pela medicina oriental, observamos ainda resistência às práticas não alopáticas entre os entrevistados.

\section{Conhecimento dos Professores sobre Acupuntura}

Tentamos explorar os conhecimentos sobre acupuntura junto aos entrevistados, questionando sobre indicações e contraindicações. Obtivemos como respostas mais recorrentes para indicações: dores crônicas de origem osteomuscular, tabagismo, obesidade e sintomas psicossomáticos. Poucos conheciam alguma contraindicação, tendo referido: distúrbios de coagulação, hemofilia, uso de medicamentos anticoagulantes, sida, risco de contaminação, resistência do paciente ao tratamento e gravidez. Em meio às respostas obtidas, observamos pouco domínio sobre o tema, evidenciado nas falas:

Contraindicação? Paciente não querer. A indicação vai depender do médico; se o paciente aceitar, você tem que explicar a ele como é que funciona, o que é. Se ele aceitar... Contraindicação? Não sei, eu acho que aids? O paciente tem medo de a agulha contaminar? Não sei... (Professor 8)
Conheço mais é dor crônica, é dor relacionada com estados depressivos, que poderiam estar associados, eu já li alguma coisa sobre isso. E obesidade, tratamento de obesidade com acupuntura, é basicamente isso, muita dor muscular, muita dor relacionada com articulação, com osso.A senhora conhece alguma contraindicação? Acho que plaquetopenia grave, alguma coisa que pode dar sangramento. Acho que não tem muita contraindicação.(Professor 14)

Contudo, segundo a literatura, são poucas as contraindicações da acupuntura evidenciadas, as quais se resumem a prescrição e uso no período da gestação, sobre dermatites ou áreas tumorais e em portadores de marca-passo ${ }^{13,28-29}$.

Desta forma, em concordância com o interesse da natureza não acadêmica demonstrado, colhemos respostas que evidenciam conhecimento leigo sobre o tema, ao mesmo tempo em que revelam incompatibilidade prático-ideológica, caracterizada por reconhecimento da importância do tema, em contraste com a não valorização de seu aprendizado para a prática médica e de ensino.

Do ponto de vista técnico, as ideias que surgem sobre a acupuntura são de uma prática alternativa ou complementar, não maléfica, mas não necessariamente benéfica, e a de terapia eficaz. Assim, da maior parte dos discursos dos médicos entrevistados, apreendemos a concepção de superioridade ou protagonismo da medicina baseada em evidências. Estando esse lugar de soberania resguardado, as ideias são evidenciadas como uma prática que deve se relacionar com a alopatia.

No caso desse método terapêutico como prática alternativa, a acupuntura é entendida como uma opção terapêutica para aqueles casos em que não pode haver, ou em que não houve após diversas tentativas, sucesso terapêutico com a alopatia. Relacionada à complementaridade, essa prática é concebida como algo que vai potencializar o resultado das condutas cientificamente legitimadas. A diferença dessa concepção para a de terapia eficaz se revela na diferença qualitativa das relações de coexistência. Em ambas, as duas racionalidades podem coexistir. No entanto, na primeira, há uma coexistência hierarquizada, em que a medicina dita científica ocupa um lugar de centralidade, detendo, assim, determinado poder sobre a outra; e, na segunda, há uma coexistência descentralizada, donde suas diferentes implicações são basicamente instituídas para as ideias políticas.

\section{Prática e Ensino: Divergências e Convergências quanto à Atuação de outros Profissionais da Área da Saúde}

A quase totalidade dos entrevistados apresentou opinião favorável sobre a acupuntura ser oferecida aos usuários do SUS, e 
alguns questionaram a qualidade do serviço que seria prestado, tendo em vista os seguintes aspectos: (a) a democratização do ensino da acupuntura para todos os profissionais de saúde, não havendo, aparentemente, exigência de intimidade com conhecimentos anatomofisiopatológicos como pré-requisito; (b) a não observância de que a acupuntura constitui um conjunto de saberes concebidos em um contexto diferenciado do modelo biomédico, sendo o respeito a esta estrutura essencial para o sucesso do tratamento, ou seja, tão importante quanto a habilidade na manipulação das agulhas e o domínio da técnica seria a observação da dimensão energética envolvida neste processo saúde-doença. É o que nos apontam as seguintes falas:

Eu acho que a acupuntura, para ser bem feita, demanda que o profissional apreenda um outro paradigma sobre o corpo, sobre a vida, sobre a nossa relação com o cosmos e com a nature$z a$, sobre o que a doença significa no processo de vida de cada um. É um paradigma muito diferenciado, onde a acupuntura nasceu, dentro da cultura oriental, e é isso que dá potência a ela enquanto uma ferramenta terapêtica e de cuidado à saúde. Então, você simplesmente isolar um conjunto de aguIhas a serem inseridas nos pontos $a, b$ ou c, sem que isso seja antecedido de uma escuta do paciente e de uma compreensão do problema que ele está vivendo dentro desse outro paradigma, que não é um paradigma médico, não é um paradigma ocidental, flexneriano, eu acho que é fundamental esse outro olhar. (Professor 4)

Então, frequentemente, uma pessoa que não é da área, não tem conhecimento da doença de base, ela não tem conhecimentos de anatomia, de fisiologia suficientes para entender o processo mórbido que está acontecendo, que o paciente apresenta. Então, como é que vai tratar? Para tratar é necessário conhecer muito bem, inclusive para detectar situações de risco. Muitas vezes, você retarda o tratamento de algumas condições porque está tentando medidas paliativas. (Professor 5)

Através do projeto de Política Nacional de Práticas Integrativas e Complementares (PNPIC), regulamentado pelo Conselho Nacional de Saúde e aprovado em 2006 pelo Ministério da Saúde, institucionaliza-se o acesso do usuário do SUS à acupuntura dentre outras opções terapêuticas, bem como se regulariza a atuação de outros profissionais de saúde nesta categoria de atenção à saúde em todo o território nacional ${ }^{17}$. Historicamente, os fisioterapeutas foram os precursores em normatizar a atividade de acupunturista, exigindo-se a conclusão de curso específico vinculado a entidade de acupuntura de reconhecida idoneidade científica ou à universidade ${ }^{18}$.
Estudos têm mostrado aumento da demanda por consultas de acupuntura no SUS, bem como aumento da atuação de médicos e outros profissionais da saúde nesta área ${ }^{30-32}$.

\section{Inclusão da Acupuntura na Grade Curricular do Curso de Medicina}

Congruentescom a tendência pedagógica da faculdade, que valoriza o diálogo entre os diversos saberes, os professores responderam que são favoráveis à inclusão da acupuntura na grade curricular como disciplina optativa ou como temática coadjuvante em disciplinas afins. Justificam que essa inserção irá colaborarpara auxiliar o aluno a explorar as potencialidades das terapias, ainda consideradas não usuais, mas que estão ganhando espaço na preferência dos pacientes.

Segundo alguns discursos, o ambiente acadêmico fornece o palco apropriado à legitimação da acupuntura como atividade médica, formalizando o encontro de futuros profissionais com o que há de novo na medicina e capacitando-os a filtrar as informações adquiridas em meio leigo, que é passível de credibilidade científica. Contudo, poucos entrevistados admitem abordar este tema em sala de aula como terapêutica complementar às opções alopáticas. Aqueles que o fazem referem que a abordagem ocorre de forma superficial e embutida em outros assuntos, tais como a relação médico-paciente, terapias alternativas e atualização terapêutica, conforme citam:

Se a gente quer a acupuntura como atividade médica, acho que ela tem que entrar na grade curricular. Como uma disciplina ou dentro de alguma disciplina, mas ela tem que entrar na graduação. Porque a gente já perdeu algumas atividades que antes eram médicas para outros profissionais pelo simples fato de não conter essa atividade na graduação e essa atividade estar em outros cursos, na graduação de outros cursos. Por conta disso, a gente perdeu esse tipo de atividade. E isso não é só uma questão de mercado, é uma questão de benefício para o paciente. Às vezes, as pessoas esquecem que a finalidade da nossa atividade é o paciente e fica lutando mais por mercado. (Professor 15)

Não, eu não abordo. Ah, por exemplo, a homeopatia, eu costumo conversar com eles sobre homeopatia. No entanto, sempre tento colocar para eles que há necessidade de conhecer esses métodos e não simplesmente se referir a eles sem conhecimento, e depois que conhecerem as bases, que eles possam tomar uma decisão. Mas eu não estimulo a falar bem ou falar mal, ou nada relativo à fé. Eu acho que aí o problema não é fé. Fé é outra coisa. O que a gente propõe para os alunos é que tenham base, tenham uma sustentação de conhecimentos por trás da prescrição que fazem. É importante que eles conheçam as coisas antes de tomar qualquer decisão. (Professor 5) 
Estudo realizado com estudantes de Medicina da Faculdade de Medicina da Universidade de São Paulo concluiu que os entrevistados apresentam interesse no estudo acadêmico de forma eletiva em acupuntura, em reconhecimento da importância desta ferramenta na educação médica ${ }^{20}$. Em outras regiões do País, esta realidade se repete na comunidade acadêmica, evidenciando o interesse das novas gerações de médicos em considerar na abordagem do paciente não apenas os aspectos anatomofisiopatológicos, mas também o contexto psicossocial $^{21-22}$. Lorio e colaboradores ${ }^{33}$ nos mostram que esta afinidade se estende para além da graduação médica, se expressando também nas escolhas de especializações realizadas após a conclusão do curso de graduação.

\section{Acupuntura: Efeito Placebo ou Tábua de Salvação?}

Os entrevistados depositam credibilidade no poder terapêutico da acupuntura, embora alguns desconfiem que o resultado positivo possa estar relacionado ao efeito placebo. Experiências pessoais e com familiares geraram respostas controversas, mostrando melhora do quadro clínico em alguns casos, ao passo que, para outros, a sintomatologia foi pouco alterada:

Também não tenho como avaliar, já vi algumas pessoas relatarem bons resultados, mas eu não tenho experiência em se ela faz o que promete ou pelo menos o que dizem. Deve ser muito boa como modalidade terapêutica. Eu tive umas experiências com pessoas da família e tudo em relação à dor; por exemplo, alguns referiram melhora, outros referiram que não adiantou de muita coisa. Então, eu não sei qual o efeito real ou se só é o efeito psicológico da pessoa, mas eu não posso dizer nada... (Professor 2)

É essa avaliação positiva, como prática terapêutica, como prática preventiva, como prática de autoconhecimento, aquele tempo que você está ali parado, numa sala calma, silenciosa, com pouca iluminação, que você está convidado a interromper essa pulga que pula no nosso cérebro ocidental o tempo inteiro e nos faz ficar pulando o tempo inteiro de um pensamento ao outro e com isso perder o contato com as coisas que são essências dentro de si mesmo e no cosmo. Esse momento que a acupuntura propicia tem também um sentido de você parar e escutar seu corpo, escutar suas dores, escutar seus sintomas, compreendê-los no contexto da vida... (Professor 4)

Rang e colaboradores ${ }^{34}$ nos trazem que o placebo é um remédio simulado, que não contém ingrediente ativo,ou, também, uma simulação de procedimento cirúrgico, dieta ou outro tipo de intervenção terapêutica que o paciente acredita que é (ou que pode ser, no contexto de um teste com controle) a coisa real.Muitos estudiosos têm voltado sua atenção para tentar esclarecer a complexidade do efeito placebo. Embora este esclarecimento ainda não tenha ocorrido, pesquisa com médicos clínicos e reumatologistas norte-americanos mostrou largo uso desse efeito com o objetivo de promover o bem-estar do paciente ${ }^{35}$.

Em um contexto de medicalização das ações e serviços de saúde, tão difundido no campo da saúde nas últimas décadas, a utilização de medicamentos alopáticos e fórmulas farmacêuticas é prioritária sobre qualquer outra intervenção. Assim, a acupuntura aparece para os entrevistados como única opção quando todos os meios utilizados foram esgotados, numa espécie de "fórmula milagrosa", conforme mostram os discursos de alguns professores entrevistados no estudo:

Já procurou tudo e não deu certo, vai procurar a acupuntura [risos] (Professor 1)

E uma outra alternativa foi exatamente a acupuntura, que sempre deu resultados bastante positivos, que realmente foram casos mais graves, cronificados e conseguiam melhorar suas dores com atendimento permanente na acupuntura. Certo?(Professor 2)

A acupuntura é eficiente no tratamento de uma infinidade de patologias ocidentais, incluindo dores agudas e crônicas, ansiedade, insônia, depressão, gastrite, asma brônquica, dentre outras ${ }^{29}$. Contudo, os professores entrevistados relataram que o principal motivo pelo qual encaminham os pacientes para a acupuntura seria a dor, principalmente a crônica, que não responde bem à terapêutica convencional:

Primeiro com dor crônica, como no caso de enxaqueca, fibromialgia, essas dores articulares. (Professor 12)

Eu já encaminhei paciente com dor. Eu tenho relacionado dor com acupuntura exatamente por isso, porque eu já encaminhei paciente com dor. Era um caso de dor crônica que fez tratamento com acupuntura. (Professor 15)

\section{Escolha Terapêutica: um Exercício de Respeito à Autonomia do Paciente}

Os professores entrevistados foram unânimes em informar que respeitam o fato de o paciente procurar o atendimento de acupuntura, inclusive abordando a possibilidade de convivência pacífica entre as duas modalidades de tratamento:

Eu costumo aceitar as opções terapêuticas mesmo alternativas, eu acredito muito que existe o efeito da fé de cada pessoa, de cada indivíduo num determinadotratamento, numa deter- 
minada conduta, e eu não sou de criticar a escolha de ninguém. Eu acredito que haja uma possibilidade de convivência das duas coisas. (Professor 10)

Em outro momento, o discurso dos professores é centrado na prudência quanto à aplicação da acupuntura como tratamento único. Assim, eles concordam e encorajam os pacientes a procurarem outra forma de tratamento, desde que este não interfira ou prejudique o tratamento que estava sendo instituído de acordo com os preceitos da medicina ocidental:

Aceitaria a solução dele. Desde que não fosse, por exemplo, se fosse uma situação em que, para mim, ele estaria sendo prejudicado se não aceitasse outro tipo de terapêutica, eu tentaria esclarecer. Mas eu acho que eu teria que respeitar a decisão dele, embora tentasse conversar e explicar o que é que eu pensava a respeito não da acupuntura, que eu não conheço, mas da outra terapêutica que eu conheço. (Professor 2)

Quando os pacientes querem fazer qualquer tipo de intervenção terapêutica alternativa aotratamento clássico daquele tipo de doença, a minha posição normalmente é que eles façam, desde que, se há outra coisa que possa ser feita, ele não deixe de fazer. (Professor 14)

Desta forma, este aspecto pode representar uma contraindicação importante para o uso da técnica. Isto porque iniciar o tratamento com acupuntura antes de firmar um diagnóstico adequado para a doença apresentada - haja vista que a acupuntura pode mascarar ou alterar os sintomas clínicos em algumas patologias- poderá dificultar, mais tarde, um diagnóstico mais acurado ${ }^{29}$. Portanto, há necessidade de prudência e bom senso para a indicação da acupuntura, seja entre médicos e profissionais da saúde, seja entre pessoas leigas.

Segundo o Código de Ética Médica ${ }^{36,37}$, é vedado ao médico "deixar de garantir ao paciente o exercício do direito de decidir livremente sobre sua pessoa ou seu bem-estar, bem como exercer sua autoridade para limitá-lo". Em reconhecimento a estas normas, os entrevistados foram unânimes em assumir uma postura respeitosa de acolhimento ao paciente adepto desta terapêutica, referindo ainda transmitir esta ideia em sala de aula.

\section{CONCLUSÕES}

A partir dosdiscursos analisados, ficou evidente o embate teórico e prático entre as percepções que sofrem a influência flexneriana e o pensamento emergente da abordagem integral do indivíduo segundo sua natureza biopsicossocial. Ao mesmo tempo em que a maioria reconhece a importância desta temática para o exercício da docência, negligencia sua abordagem enquanto médico e, principalmente, professor, demonstrando dificuldades para articular o objeto das aulas - diretamente relacionado com a racionalidade ocidental/científica - com outra visão mais ampliada sobre o corpo e o adoecer.

Ao explorarmos o nível de conhecimento clínico sobre o tema, nos deparamos com respostas negativas ou imprecisas, que demonstram pouca ou nenhuma intimidade com esta ferramenta terapêutica.A partir do perfil dos entrevistados, verificamosque durante anos não houve preocupação no ensino médico em abordar as terapêuticas complementares no currículo como parte de sua formação, o que nos faz pressupor essa pouca aproximação com o tema apontada pelos entrevistados.

Foi mencionado interesse na inclusão da acupuntura na grade curricular do curso de Medicina, diluída em alguma disciplina ou como disciplina optativa.

No que se refere às afirmações sobre encaminhamento de pacientes ao tratamento com acupuntura, observamos respeito à autonomia do paciente quanto à decisão da opção terapêutica pretendida.

Os entrevistados divergiram quanto ao exercício da acupuntura por outros profissionais da área da saúde. Para uns, a formação médica não oferece suporte ao exercício de uma prática alicerçada e concebida numa realidade divergente daquela da medicina ocidental; para outros, a prática da acupuntura prescinde da sedimentação de conhecimentos anatomofisiopatológicos, não encontrados em outros cursos da área da saúde.

O estudo não elucidou todos os problemas que entrelaçam as questões que envolvem o ensino da acupuntura no contexto atual do ensino médico. Entretanto, mostrou a existência de fatores que podem contribuir para que a prática da acupuntura esteja mais acessível aos pacientes, o que depende, em parte, do grau de conhecimento repassado aos alunos durante a formação acadêmica.

Conclui-se que os professores que participaram deste estudo necessitam de mais subsídios para compreender a gênese da acupuntura e sua aplicação clínica, bem como de mais discussões entre eles sobre a prática da acupuntura e seu ensino na graduação.

\section{REFERÊNCIAS}

1. Scognamillo-Szabo MVR, Bechara GH. Acupuntura: bases científicas e aplicações. Ciênc Rural. 2001;31(6):1091-9.

2. Maciocia G. Os fundamentos da medicina chinesa: um texto abrangente para acupunturistas e fisioterapeutas. São Paulo: Roca; 2007.

3. Voisin H. Acupuntura para o clínico geral. 6ª ed. São Paulo: Andrei; 1983 
4. Alem MER. A acupuntura na reabilitação de mulheres após tratamento cirúrgico do câncer de mama. Campinas, 2005. Doutorado [Tese]- Universidade Estadual de Campinas. Faculdade de Ciências Medicas.

5. Cassileth B, Trevisan C, Gubili J. Complementary therapies for cancer pain. Curr Pain Headache Rep. 2007;11(4):265-9.

6. Cassileth BR, Deng GE, Gomez JE, Johnstone PA, Kumar $\mathrm{N}$, Vickers AJ. Complementary therapies and integrative oncology in lung cancer: ACCP evidence-based clinical practice guidelines. Chest. 2007;132(3 Suppl):340S-54S.

7. World Health Organization. New WHO guidelines to promote proper use of alternative medicines. 2004 [online] [acesso em 20 fev 2008]. Disponível em: http:/ / www.who. int/mediacentre/news/releases/2004.

8. Góis ALB. Acupuntura, especialidade multidisciplinar: uma opção nos serviços públicos aplicados a idosos. Rev Bras Geriatr Gerontol. 2007;10(1):73-86.

9. Carvalho Filho ET. Iatrogenia em pacientes idosos hospitalizados. Rev Saúde Pública. 1998; 32(1):36-42.

10. Góis ALB. Acupuntura, especialidade multidisciplinar: uma opção nos serviços públicos aplicados a idosos. Rev Bras Geriatr Gerontol. 2007;10(1):73-86.

11. Scognamillo-Szabo MVR, Bechara GH. Acupuntura: bases científicas e aplicações. Ciênc Rural. 2001;31(6):1091-9.

12. Andersson $S$. The functional background in acupuncture effects. Scand J Rehabil Med. 1993; 29(Suppl):31-60.

13. Luz MT. Cultura contemporânea e medicinas alternativas: novos paradigmas em saúde no fim do século XX.Physis. 1997;7(1):13-43.

14. Nogueira MI, Camargo Júnior KR. A orientalização do Ocidente como superfície de emergência de novos paradigmas em saúde. Hist Ciênc Saúde-Manguinhos. 2007;14(3):841-61.

15. Bechara GH. Acupuntura: bases científicas e aplicações. Ciênc Rural 2001;31(6):1091-9.

16. Burk A, Upchurch DM, Dye C, Chyu L. Acupuncture use in the United States: findings from the National Health Interview Survey. J Altern Complement Med. 2006;12(7):639-48.

17. Conselho Federal de Medicina. Resolução CFM no 1.455/95 [online]. [acesso em 27 jan. 2011]. Disponível em:http://www.portalmedico.org.br/resolucoes / CFM/1995/1455_1995.htm.

18. Brasil. Ministério da Saúde. Portaria n⿳0 971, de 3 de maio de 2006 [online]. [acesso em 2 jan. 2010] Disponível em: http: / / portal.saude.gov.br/portal/arquivos/pdf/PNPIC.pdf.

19. Conselho Federal de Fisioterapia e Terapia Ocupacional. Resolução COFFITO nº. 97 de 22 de abril de 1988. Baixa atos complementares à Resolução COFFITO-60, que dis- põe sobre a prática da acupuntura pelo Fisioterapeuta, e dá outras providências [online]. [aceso em 27 jan. 2011]. Disponível em: http://www.coffito.org.br/publicacoes/ pub_view.asp?cod=1024\&psecao $=9$.

20. Conselho Federal de Enfermagem. Resolução COFEN n ${ }^{\circ}$ 197/1997. Estabelece e reconhece as terapias alternativas como especialidade e/ou qualificação do profissional de Enfermagem [online]. [acesso em 27 jan. 2011]. Disponível em: http://www.abenanacional.com.br/Resolucao\%20 COFEN\%20197\%201997.pdf.

21. Amadera JED, Pai HJ, Hsing WT, Teixeira MZ, Martins MA, Lin CA. The teaching of acupuncture in the University of São Paulo School of Medicine, Brazil. Rev Assoc Med Bras. 2010;56(4):458-61.

22. Kulkamp IC, Burin GD, Souza MHM, Silva P, Piovezan AP. Aceitação de práticas não-convencionais em saúde por estudantes de medicina da Universidade do Sul de Santa Catarina. Rev Bras Educ Med. 2007;31(3):229-35.

23. Christensen MC, Barros NF. Medicinas alternativas e complementares no ensino médico: revisão sistemática. Rev Bras Educ Med. 2010;34(1):97-105.

24. Bosi MLM, Mercado FJM. Pesquisa qualitativa de serviços de saúde. Petrópolis, RJ: Vozes; 2004.

25. Neves JL. Pesquisa qualitativa: características, usos e possibilidades. Cad Pesq Adm [periódico na internet]. 1996. 1(3) [capturado 29 fev. 2008]. Disponível em: http:/ / www. ead.fea.usp.br/cad-pesq/arquivos/C03-art06.pdf.

26. Minayo MCS. O desafio do conhecimento: pesquisa qualitativa em saúde. 10ª ed. São Paulo: Hucitec; 2008.

27. Queiroz MS. O paradigma mecanicista da medicina ocidental moderna: uma perspectiva antropológica. Rev Saúde Pública. 1986;20(4):309-17.

28. Capra F. O ponto de mutação. São Paulo: Cultrix; 1986.

29. Bannerman RH. The World Health Organization view point on acupuncture. Am J Acupunct. 1980; 8(3):231-5.

30. Scognamillo-Szabo MVR, Bechara GH. Acupuntura: histórico, bases teóricas e sua aplicação em Medicina Veterinária. Ciênc Rural. 2010;40(2):491-500.

31. Cintra MER, Figueiredo R. Acupuntura e promoção de saúde: possibilidades no serviço público de saúde.Interface Comun Saúde Educ 2010;14(32):139-54.

32. Santos FAZ, Gouveia GC, Martelli PJL, Vasconcelos EMR. Acupuntura no Sistema Único de Saúde e a inserção de profissionais não-médicos. Rev Bras Fisioter 2009;13(4):330-4.

33. Rodrigues Neto JF, Faria AA, Figueiredo MFS. Medicina complementar e alternativa: utilização pela comunidade de Montes Claros, Minas Gerais. Rev Assoc Med Bras. 2009;55(3):296-301 
34. Iorio RC, Siqueira AAF, Yamamura Y. Acupuntura: motivações de médicos para a procura de especialização.Rev Bras Educ Med. 2010;34(2):247-54.

35. Rang HP, Dale MM, Ritter JM, Moore PK. Farmacologia. 5⿳亠丷. ed. Rio de Janeiro: Elsevier; 2004.

36. Tilburt JC, Emanuel EJ, Kaptchuk TJ, Curlin FA, Miller FG. Prescribing "placebo treatments": results of national survey of US internists and rheumatologists. BMJ. 2008;337:1938.

37. Conselho Federal de Medicina. Resolução CFM no ${ }^{\circ}$ 1.931, de 17 de setembro de 2009. Aprova o Código de Ética Médica [online]. [acesso em 25 jan. 2011]. Disponível em: http:/ / www.cremesp.org.br/library / modulos/legislacao/versao_impressao.php?id=8822

\section{CONTRIBUIÇÃO DOS AUTORES}

Todos os autores participaram da concepção do estudo, pesquisa de campo, análise e revisão do artigo.

\section{CONFLITO DE INTERESSES}

Declarou não haver.

\section{ENDEREÇO PARA CORRESPONDÊNCIA}

Márcia Maria Tavares Machado

Faculdade de Medicina UFC

Rua Prq. Costa Mendes, 1609 - 5ㅇa andar

Rodolfo Teofilo - Fortaleza

CEP. 60430-120 - CE

E-mail: marciamachado@ufc.br. 